\title{
Keanekaragaman laba-laba dan potensinya sebagai musuh alami hama tanaman jambu mete
}

\author{
Diversity of spiders and their potentials as natural enemies \\ of cashew pests
}

\author{
I Wayan Suana ${ }^{1 *}$, Hery Haryanto ${ }^{2}$ \\ 'Program Studi Biologi, Fakultas Matematika dan Ilmu Pengetahuan Alam, \\ Universitas Mataram, Jalan Majapahit No. 62, Mataram 83125 \\ ${ }^{2}$ Program Studi Agroteknologi, Fakultas Pertanian, Universitas Mataram, \\ Jalan Pendidikan No. 37, Mataram 83125
}

(diterima Januari 2013, disetujui Maret 2013)

\begin{abstract}
ABSTRAK
Sanurus sp., Acrocercops sp. dan Helopeltis sp. merupakan hama-hama penting tanaman jambu mete yang dilaporkan di Nusa Tenggara Barat. Penggunaan pestisida untuk mengendalikan hamahama tersebut ternyata kurang berhasil sehingga dicari alternatif, yaitu dengan menggunakan musuh alami. Laba-laba merupakan salah satu musuh alami yang ditemukan di perkebunan jambu mete. Tujuan penelitian ini adalah untuk mengetahui keanekaragaman dan potensi pemangsaan laba-laba di perkebunan jambu mete. Penelitian dilakukan di Dusun Jugil, Desa Sambik Bangkol, Lombok Utara. Pemangsaan laba-laba diamati secara langsung selama 78 hari, mulai bulan Mei sampai Agustus 2009. Formula Edgar digunakan untuk mengetahui pemangsaan laba-laba per hari. Hasil penelitian menemukan 19 spesies dari delapan famili laba-laba. Kelimpahan Neoscona theisi lebih tinggi daripada Tetragnatha maxillosa, tetapi proporsi $N$. theisi dengan mangsa lebih rendah daripada T. maxillosa, sehingga kemelimpahan laba-laba pada pertanaman jambu mete belum tentu menunjukkan potensinya sebagai musuh alami. $N$. nautica memangsa lebih banyak dibandingkan dengan $N$. theisi, yaitu berturut-turut 3,84 dan 1,67 mangsa per hari. Tidak semua mangsa $N$. nautica merupakan hama tanaman jambu mete, sebaliknya semua mangsa $N$. theisi merupakan hama tanaman jambu mete. Hal ini menunjukkan bahwa, jumlah mangsa yang dimangsa laba-laba per hari tidak secara langsung menunjukkan potensinya sebagai musuh alami.
\end{abstract}

Kata kunci: hama jambu mete, musuh alami, laba-laba

\begin{abstract}
Sanurus sp., Acrocercops sp. and Helopeltis sp. are important pests of cashews in Nusa Tenggara Barat. Pesticide usage to control these pests has so far not been successful, and thus the usage of natural enemy as an alternative control methods should be developed. Spider represents one of the natural enemies which are found in cashew plantation. The aims of the research is to study spider population and its predatory ability in cashew plantation. The study has been conducted in an area of cashew plantation at Dusun Jugil, Desa Sambik Bangkol, Lombok Utara. Spider predation was directly observed for 78 days, starting from May to August 2009. Edgar formula was used to measure spider predation per day. The study found 19 species of spider consisting from eight families. The abundance of Neoscona theisi is higher than Tetragnatha maxillosa, but the proportion of $N$. theisi with prey is less than T. maxillosa. This phenomenon indicates that spider's abundance, does not directly show its potential as natural enemy in that habitat. $N$. nautica consumed at least 3.84 preys per day, but not all of its prey represents the pest of cashew. $N$. theisi consumed 1.67 preys per day and all of its prey represents pests of cashew. This study show that the amount of prey which can
\end{abstract}

\footnotetext{
*Penulis korespondensi: I Wayan Suana. Program Studi Biologi, Fakultas Matematika dan Ilmu Pengetahuan Alam,

Universitas Mataram, Jalan Majapahit No. 62 Mataram 83125

Tel: 0370-646506, Faks: 0370-646506, Email: iwayansuana.unram@gmail.com
} 
be consumed by spider per day does not directly show the potential of spiders as natural enemey of cashew pest.

Key words: cashew pest, natural enemy, spider

\section{PENDAHULUAN}

Jambu mete (Anacardium occidentale Linn.) merupakan salah satu komoditas unggulan di Nusa Tenggara Barat (NTB) dengan luas areal mencapai 56.000 ha. Khusus di Pulau Lombok luasnya mencapai 26.285 ha, yang sebagian besar terdapat di Kabupaten Lombok Utara, yaitu 21.436 ha (DPNTB 2009).

Serangan organisme pengganggu tanaman (OPT) merupakan salah satu kendala dalam upaya pengembangan jambu mete di NTB. OPT yang merupakan hama penting tanaman jambu mete di NTB, yaitu Sanurus sp. (Hemiptera: Flatidae), Acrocercops sp. (Lepidoptera: Gracillariidae) dan Helopeltis sp. (Heteroptera: Miridae) (DPNTB 2009). Serangan hama tersebut telah menyebabkan penurunan produksi buah sebesar $17,8 \%$ sampai 28,2\% (DPNTB 2003).

Petani di Lombok Utara umumnya menggunakan pestisida untuk mengendalikan hama tersebut namun hasilnya tidak optimal karena dari tahun ke tahun gejala serangan terus meningkat. Seluas 1.150 ha tanaman jambu mete di Lombok Utara terserang hama tersebut pada tahun 2000. Selang dua tahun kemudian serangan meningkat tiga kali lipat menjadi 3.432 ha (DPNTB 2003). Pada akhir tahun 2008, sekitar 30\% (6.430,8 ha) areal pertanaman jambu mete di Lombok Utara terserang hama tersebut (DPNTB 2009). Oka \& Bahagiawati (1991) menyatakan bahwa pengendalian hama dengan satu cara pendekatan, seperti penggunaan pestisida saja, terbukti tidak cukup dan sering kurang berhasil. Berdasarkan fenomena tersebut maka diperlukan upaya pengendalian yang efektif untuk menekan pertumbuhan populasi hama serta tidak berdampak buruk terhadap lingkungan di sekitarnya. Salah satunya adalah dengan menggunakan musuh alami hama.

Laba-laba merupakan salah satu musuh alami hama (predator), terutama terhadap serangga sehingga dapat berperan dalam mengontrol populasi serangga. Laba-laba adalah predator polifag sehingga berpotensi untuk mengendalikan berbagai spesies serangga hama (Nyffeler \& Sunderland 2003; Chatterjee et al. 2009). Labalaba mampu menempati berbagai macam habitat sehingga bisa berpindah dari satu habitat ke habitat lainnya bila mengalami gangguan (Suana et al. 2005; Öberg et al. 2008; Hogg \& Daane 2010). Penelitian ini bertujuan mengetahui keanekaragaman dan potensi laba-laba sebagai musuh alami hama tanaman jambu mete di Kabupaten Lombok Utara.

\section{BAHAN DAN METODE}

Penelitian dilaksanakan pada pertanaman jambu mete di Dusun Jugil, Desa Sambik Bangkol, Lombok Utara. Luas areal pertanaman jambu mete yang dipakai untuk pengamatan pemangsaan labalaba terhadap hama tanaman jambu mete adalah 0,5 ha. Rata-rata pengamatan per hari adalah 6-7 jam sehingga lama pengamatan adalah 78 hari yang dimulai dari bulan Mei sampai Agustus 2009.

\section{Pelaksanaan penelitian}

Tingkat predasi laba-laba diketahui dari pengamatan aktivitas dan penghitungan secara langsung laba-laba yang sedang memangsa hama tanaman jambu mete di lapangan. Pengamatan dilakukan selama 24 jam untuk satu kali periode pengamatan. Waktu pengamatan dibagi dalam delapan rentang waktu, yaitu pukul 00:0103:00, 03:01-06:00, 06:0-09:00, 09:01-12:00, 12:01-15:00, 15:01-18:00, 18:01-21:00, dan 21:01-24:00. Jika data pada salah satu rentang waktu tersebut tidak ada karena tidak dilakukan pengamatan maka pengamatan dilakukan pada hari berikutnya pada waktu yang sesuai dengan rentang waktu yang datanya tidak ada, sehingga datanya menjadi lengkap 24 jam. Demikian seterusnya sampai pengamatan berlangsung selama 524 jam. Pengamatan pada malam hari menggunakan lampu petromaks dan senter. Labalaba yang terlihat sedang memangsa hama tanaman jambu mete dicatat. Sebagai data penunjang untuk mendukung keterkaitan antara tingkat pemangsaan dan kelimpahan hama tanaman jambu 
mete sebagai mangsa, dilakukan pengamatan kelimpahan hama tanaman jambu mete. Sampel diambil dengan menggunakan jaring ayun pada 10 tanaman jambu mete yang ditentukan secara acak. Jaring ayun diayun-ayunkan sebanyak 20 kali pada tajuk tanaman yang terpilih sebagai sampel. Serangga yang tertangkap pada jaring ayun diambil dengan aspirator, kemudian disimpan dalam botol koleksi dan diawetkan dengan alkohol 70\% untuk diidentifikasi di Laboratorium Biologi, Fakultas Matematika dan Ilmu Pengetahuan Alam, Universitas Mataram.

\section{Analisis data}

Penentuan jumlah mangsa yang dimangsa oleh seekor laba-laba per hari menggunakan formula Edgar sebagai berikut:

$$
b=\frac{\mathrm{T}_{\mathrm{f}} \cdot \mathrm{w}}{\mathrm{T}_{\mathrm{h}}} \text {, dengan }
$$

$b$ : rata-rata mangsa yang ditangkap per hari; $\mathrm{T}_{\mathrm{f}}$ : lama waktu (jam/hari) laba-laba untuk memburu, menangkap dan memakan mangsanya; w: rata-rata proporsi laba-laba dengan mangsa yang teramati selama pengamatan; dan $\mathrm{T}_{\mathrm{h}}$ : rata-rata waktu yang diperlukan laba-laba untuk menangani mangsa (berdasarkan dugaan Holt et al. (1986), yaitu sebesar 0,72).

\section{HASIL}

Dalam pengamatan yang dilakukan dari bulan Mei sampai Agustus 2009 pada perkebunan jambu mete di Dusun Jugil, Desa Sambik Bangkol, Lombok Utara, ditemukan 19 spesies laba-laba (Tabel 1). Dari 19 spesies laba-laba tersebut, hanya delapan spesies yang teramati sedang melakukan pemangsaan, yaitu Phintella sp., Chosmophasis estrellaensis, Plexippus paykulli, Neoscona theisi, Neoscona nautica, Misumena tapyasuka, Agelena limbata dan Tetragnatha maxillosa (Gambar 1). N. theisi merupakan laba-laba yang paling sering dijumpai selama pengamatan, yaitu sebanyak 977 kali. Dari 977 kali perjumpaan dengan $N$. theisi hanya $15 \mathrm{kali}$ dijumpai sedang memangsa sehingga proporsi $N$. theisi dengan mangsa adalah 0,02. Sementara itu, proporsi T. maxillosa dengan mangsa adalah 0,14 , meskipun laba-laba ini paling jarang dijumpai.
Tabel 1. Laba-laba yang ditemukan pada perkebunan jambu mete di Dusun Jugil, Desa Sambik Bangkol, Lombok Utara (MeiAgustus 2009)

\begin{tabular}{|c|c|}
\hline Famili & Spesies \\
\hline \multirow[t]{4}{*}{ 1. Thomisidae } & 1. Monaeses habamatinikus \\
\hline & 2. Borboropactus umaasaeus \\
\hline & 3. Misumena tapyasuka \\
\hline & 4. Thomisus okinawensis \\
\hline \multirow[t]{7}{*}{ 2. Salticidae } & 5. Myrmarachne plataleoides \\
\hline & 6. Phintella sp. \\
\hline & 7. Phintella vittata \\
\hline & 8. Phintella versicolor \\
\hline & 9. Plexippus paykulli \\
\hline & 10. Cosmophasis estrellaensis \\
\hline & 11. Marpissa sp. \\
\hline \multirow[t]{3}{*}{ 3. Araneidae } & 12. Neoscona theisi \\
\hline & 13. Neoscona nautica \\
\hline & 14. Cyclosa insulana \\
\hline 4. Clubionidae & 15. Cheiracanthium liplikeum \\
\hline 5. Agelenidae & 16. Agelena limbata \\
\hline 6. Lycosidae & 17. Pardosa pseudoannulata \\
\hline 7. Tetragnathidae & 18. Tetragnatha maxillosa \\
\hline 8. Hersilidae & 19. Hersilia clathrata \\
\hline
\end{tabular}

Selama pengamatan, T. maxillosa hanya dijumpai sebanyak tujuh kali yang satu kali diantaranya sedang memangsa.

Potensi pemangsaan masing-masing spesies laba-laba ditentukan dengan menggunakan formula Edgar (Tabel 2). Laba-laba yang memiliki potensi pemangsaan paling tinggi adalah $N$. nautica dengan rata-rata jumlah mangsa per hari 3,84 . Lama waktu yang digunakan untuk melakukan kegiatan pemangsaan dalam sehari adalah 12 jam. Sementara itu, N. theisi memangsa ratarata 0,33 individu mangsa per hari, dengan lama waktu pemangsaan $12 \mathrm{jam}$. Meskipun $N$. nautica mempunyai potensi pemangsaan yang lebih besar dibandingkan dengan $N$. theisi, tetapi mangsa $N$. nautica tidak semuanya merupakan hama tanaman jambu mete (Tabel 3). Selain memangsa imago Acrocercops sp. yang ketika larva merupakan hama penggerek daun, $N$. nautica juga memangsa semut dan kumbang yang bukan merupakan hama tanaman jambu mete. Sebaliknya, mangsa $N$. theisi semuanya merupakan hama tanaman jambu mete, yaitu Acrocercops sp. dan Sanurus flavonosus.

Kelimpahan serangga hama penting tanaman jambu mete di area penelitian tergolong rendah (Tabel 4). Helopeltis sp. yang dilaporkan sebagai hama penting tanaman jambu mete di NTB tidak 

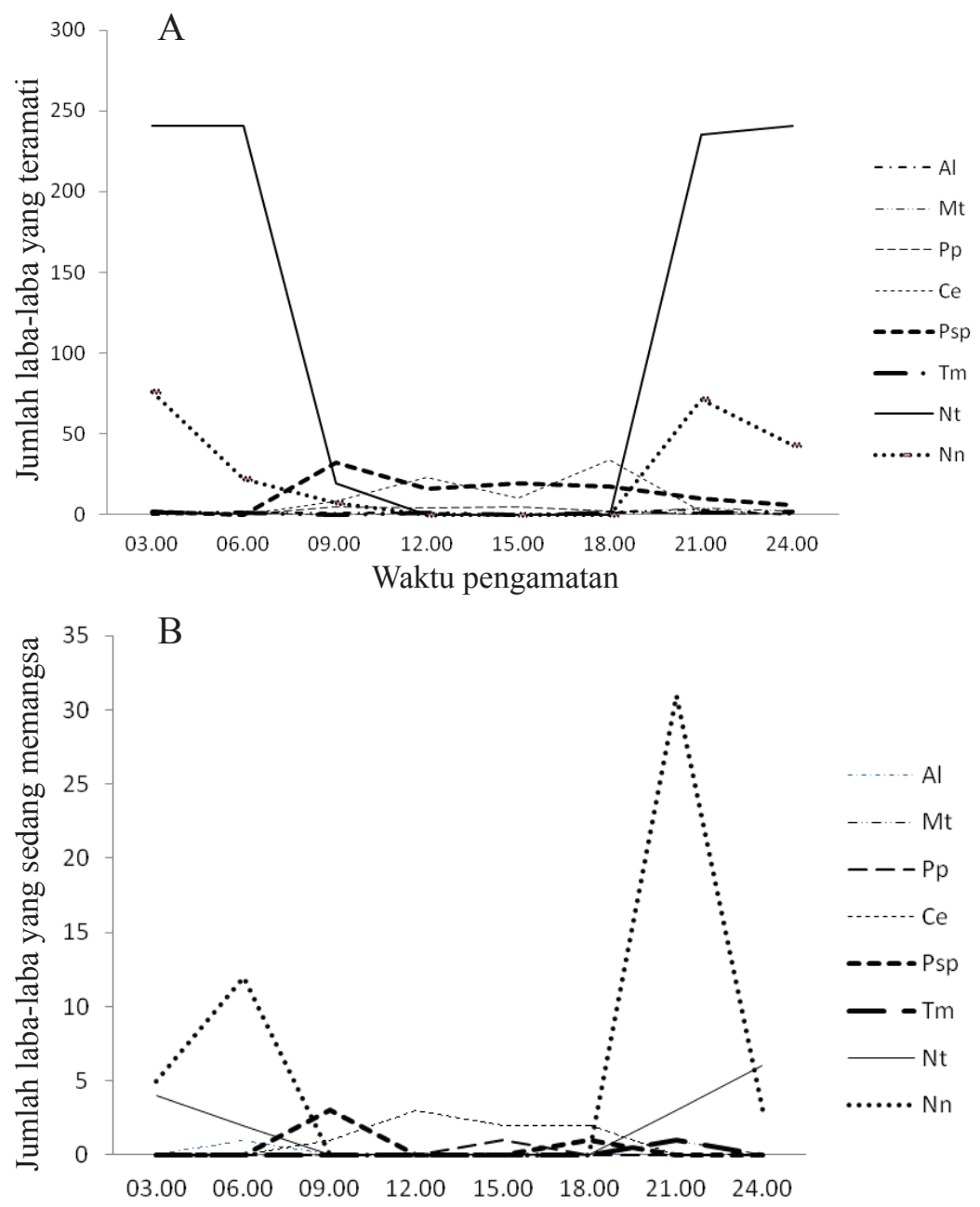

Waktu pengamatan

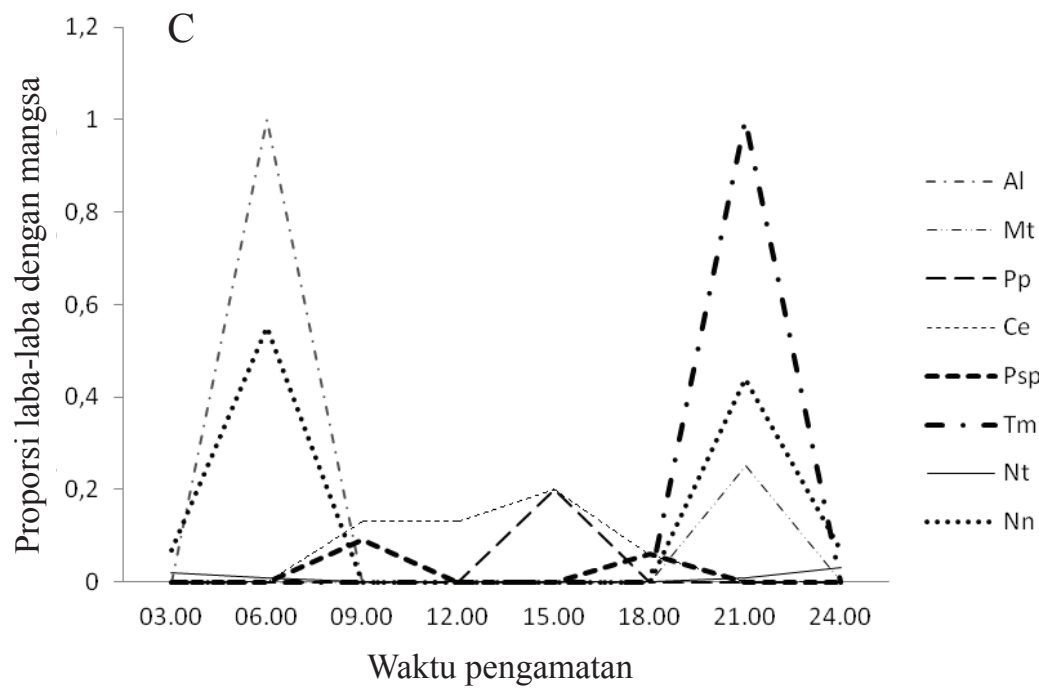

Gambar 1. Pengamatan pemangsaan laba-laba pada perkebunan jambu mete di Dusun Jugil, Desa Sambik Bangkol, Lombok Utara (Mei-Agustus 2009), (A: jumlah laba-laba yang teramati; B: jumlah laba-laba yang sedang memangsa; C: proporsi laba-laba dengan mangsa. Keterangan: Al: Agelena limbata; Mt: Misumena tapyasuka; Pp: Plexippus paykulli; Ce: Cosmophasis estrellaensis: Psp: Phintella sp.; Tm: Tetragnatha maxillosa; Nt: Neoscona theisi; Nn: Neoscona nautica). 
Tabel 2. Potensi pemangsaan laba-laba pada perkebunan jambu mete di Dusun Jugil, Desa Sambik Bangkol, Lombok Utara (Mei-Agustus 2009)

\begin{tabular}{lcccc}
\hline Spesies & Tf (jam/hari) & w & Th $(0,72)$ & b \\
\hline Agelena limbata & 3 & 0,13 & 0,72 & 0,54 \\
Misunema tapyasuka & 3 & 0,11 & 0,72 & 0,46 \\
Plexippus paykulli & 3 & 0,06 & 0,72 & 0,25 \\
Cosmophasis estrellaensis & 12 & 0,10 & 0,72 & 1,67 \\
Phintella sp. & 6 & 0,04 & 0,72 & 0,33 \\
Tetragnatha maxillosa & 3 & 0,14 & 0,72 & 0,58 \\
Neoscona theisi & 12 & 0,02 & 0,72 & 0,33 \\
Neoscona nautica & 12 & 0,23 & 0,72 & 3,84 \\
\hline
\end{tabular}

$\mathrm{T}_{\mathrm{f}}$ lama waktu (jam/hari) laba-laba untuk memburu, menangkap dan memakan mangsanya; w: rata-rata proporsi laba-laba dengan mangsa yang teramati selama pengamatan; dan $\mathrm{T}_{\mathrm{h}}$ : rata-rata waktu yang diperlukan laba-laba untuk menangani mangsa; $b$ : rata-rata mangsa yang ditangkap per hari

Tabel 3. Mangsa laba-laba pada perkebunan jambu mete di Dusun Jugil, Desa Sambik Bangkol, Lombok Utara (Mei-Agustus 2009)

\begin{tabular}{|c|c|c|c|c|c|c|c|}
\hline \multirow{2}{*}{ Spesies } & \multicolumn{7}{|c|}{ Mangsa (\%) } \\
\hline & Smt & Acr*) & $\left.\mathrm{Sf}^{*}\right)$ & $\left.\mathrm{Si}^{*}\right)$ & Kpk & Llt & $\mathrm{Kmb}$ \\
\hline Agelena limbata & & & & 100 & & & \\
\hline Misunema tapyasuka & 100 & & & & & & \\
\hline Plexippus paykulli & & & & & & & \\
\hline Cosmophasis estrellaensis & & 50 & & & 50 & 25 & \\
\hline Phintella $\mathrm{sp}$. & & 100 & & & 100 & & \\
\hline Tetragnatha maxillosa & & & 100 & & & & \\
\hline Neoscona theisi & & 82,6 & 17,4 & & 82,6 & & \\
\hline Neoscona nautica & 90,4 & 7,7 & & & 7,7 & & 1,9 \\
\hline
\end{tabular}

Smt: semut; Acr: Acrocercops sp.; Sf: Sanurus flavonosus; Si: Sanurus indecora; Kpk: kepik; Llt: lalat; Kmb: kumbang *merupakan hama penting tanaman jambu mete (Departemen Pertanian 2004; DPNTB 2009)

dijumpai pada penelitian ini. Kelimpahan Valanga sp. (Orthoptera: Acrididae) paling rendah, yaitu 1 individu per 20 kali ayunan jaring ayun atau hanya $1,7 \%$ dari total hama yang ditemukan. Kelimpahan serangga hama lainnya per 20 kali ayunan jaring ayun, yaitu $S$. indecora 2 individu (3,5\%), Acrocercops sp. 5 individu $(8,6 \%)$ dan S. flavonosus 8 individu (13,8 \%). Aphis sp. (Homoptera: Aphididae) kelimpahannya paling tinggi ditemukan pada saat penelitian, yaitu 42 individu $(72,4 \%)$.

\section{PEMBAHASAN}

Bila diasumsikan bahwa intensitas perjumpaan dengan laba-laba menunjukkan kelimpahan labalaba pada perkebunan tersebut maka kelimpahan $N$. theisi lebih tinggi dibandingkan dengan $T$. maxillosa. Meskipun $N$. theisi lebih melimpah dibandingkan dengan $T$. maxillosa, proporsinya dengan mangsa ternyata lebih rendah. Hal ini mencerminkan bahwa tingginya kelimpahan labalaba pada suatu habitat belum tentu menunjukkan 28 potensinya sebagai musuh alami hama pada perkebunan tersebut. Hal serupa juga ditemukan oleh Nyffeler \& Sunderland (2003) serta Moreno et al. (2010).

Masing-masing spesies laba-laba memiliki perbedaan waktu memangsa. A. limbata (Agelenidae), N. theisi dan N. nautica (Araneidae), T. maxillosa (Tetragnathidae) dan M. tapyasuka (Thomisidae) dijumpai paling sering melakukan pemangsaan pada malam hari. Sebaliknya, Phintella sp., C. estrellaensis dan P. paykulli (Salticidae) banyak dijumpai memangsa pada siang hari. Hal ini menunjukkan bahwa famili Agelenidae, Araneidae, Tetragnathidae dan Thomisidae merupakan laba-laba yang aktif pada malam hari atau nokturnal. Di lain pihak, Salticidae merupakan famili laba-laba yang aktif pada siang hari atau diurnal. Costello \& Daane (2005) juga mendapatkan hal yang sama, sebagian besar anggota famili Araneidae dan Lycosidae merupakan laba-laba nokturnal, sedangkan semua anggota famili Salticidae merupakan laba-laba diurnal. Ceballos et al. (2005) melaporkan bahwa 
Tabel 4. Serangga hama penting tanaman jambu mete di perkebunan jambu mete Dusun Jugil, Desa Sambik Bangkol, Lombok Utara (Mei-Agustus 2009)

\begin{tabular}{lcc}
\hline Serangga hama & $\begin{array}{c}\text { Jumlah } \\
\text { (individu per 20 kali ayunan) }\end{array}$ & Presentase \\
\hline Lepidoptera & & \\
$\quad$ Acrocercops sp. (Gracillariidae) & 5 & 8,6 \\
Hemiptera & 2 & 3,5 \\
$\quad$ Sanurus indecora (Flatidae) & 8 & 13,8 \\
Sanurus flavonosus (Flatidae) & 42 & 72,4 \\
$\quad$ Aphis sp. (Aphididae) & 1 & 1,7 \\
Orthoptera & & \\
$\quad$ Valanga sp. (Acrididae) & &
\end{tabular}

Eriophora edax (Araneidae) aktif memangsa pada pukul 19:00-23:00 dan meningkat kembali pada pukul 03:00-04:00. Fenomena ini mirip dengan yang terjadi pada $N$. nautica (Araneidae) yang ditemukan pada penelitian ini, laba-laba N. nautica aktif memangsa pada rentang waktu pengamatan pukul 18:00-21:00 kemudian meningkat lagi pada pukul 03:00-06:00.

Banyaknya jumlah mangsa yang dapat dikonsumsi oleh laba-laba per hari tidak secara langsung menunjukkan potensinya sebagai musuh alami hama tanaman jambu mete. Misalnya, $N$. nautica memangsa lebih banyak dibandingkan dengan $N$. theisi, tetapi tidak semua mangsa $N$. nautica merupakan hama tanaman jambu mete. Selain $N$. theisi, ada tiga spesies laba-laba lainnya yang mangsanya merupakan hama tanaman jambu mete, yaitu A. limbata, T. maxillosa dan Phintella sp. Ketiga spesies laba-laba ini berturut-turut memangsa Acrocercops sp., S. indecora dan $S$. flavonosus. Acrocercops sp. merugikan petani jambu mete pada fase larva karena menggerek daun mete yang masih muda, sedangkan $S$. indecora dan $S$. flavonosus merugikan petani pada fase nimfa (Departemen Pertanian 2004; DPNTB 2009). Nimfa S. indecora dan S. flavonosus mengisap cairan tanaman dan mengeluarkan cairan lengket dan manis yang merangsang pertumbuhan embun jelaga. Embun jelaga berwarna hitam pekat dapat menutupi seluruh permukaan daun sehingga mengganggu proses fotosintesis tanaman (Ellyda et al. 2001; Stella \& Sudantha 2004).

Aphis sp. (Hemiptera: Aphididae) merupakan hama yang paling melimpah ditemukan di perkebunan jambu mete pada lokasi penelitian. Ironisnya, tidak ada satupun spesies laba-laba yang ditemukan memangsanya. Hal ini kemungkinan disebabkan oleh semut rangrang (Oecophyla smaragdina) yang melindungi Aphis sp. sehingga jika ada pemangsa yang mendekat maka semut rangrang akan mengusirnya. Sebagai imbalannya semut rangrang mendapatkan embun madu dari hasil sekresi Aphis sp. pada tanaman. Simbiosis mutualisme yang melibatkan semut rangrang dan Aphis sp. inilah yang menyebabkannya luput dari pemangsaan laba-laba.

Masing-masing spesies laba-laba memiliki waktu aktif dan spesies mangsa yang berbedabeda sehingga sangat penting untuk mengelola keanekaragaman spesies laba-laba pada suatu area perkebunan. Dengan beragamnya spesies laba-laba maka potensinya untuk mengendalikan beragaman hama juga semakin besar.

\section{KESIMPULAN}

Pada perkebunan jambu mete di Dusun Jugil, Desa Sambik Bangkol, Lombok Utara terdapat 19 spesies laba-laba yang tergolong ke dalam 8 famili. N. theisi, A. limbata, T. maxillosa dan Phintella sp. berpotensi sebagai musuh alami hama tanaman jambu mete. Untuk memperbesar potensinya sebagai musuh alami hama maka sangat penting mengelola keanekaragaman labalaba pada pertanaman jambu mete.

\section{UCAPAN TERIMA KASIH}

Penghargaan dan terima kasih penulis sampaikan kepada Kementerian Pendidikan dan Kebudayaan yang telah membiayai penelitian ini, melalui DIPA P2T eks. Pembangunan Universitas Mataram Tahun Anggaran 2009 Nomor 0234.0/ 023-04.2/XXI/2009, Tanggal 31 Desember 2008. 


\section{DAFTAR PUSTAKA}

[DPNTB] Dinas Perkebunan Nusa Tenggara Barat. 2003. Laporan Tahunan Dinas Perkebunan Nusa Tenggara Barat Tahun 2002. Mataram: Dinas Perkebuanan Nusa Tenggara Barat.

[DPNTB] Dinas Perkebunan Nusa Tenggara Barat. 2009. Laporan Tahunan Dinas Perkebunan Nusa Tenggara Barat Tahun 2008. Mataram: Dinas Perkebuanan Nusa Tenggara Barat.

Ceballos L, Henaut Y, Legal L. 2005. Foraging strategies of Eriophora edax (Araneae: Araneidae): a nocturnal orb-weaving spider. Journal of Arachnology 33:509-515. http:// dx.doi.org/10.1636/04-74.1.

Chatterjee S, Isaia M, Venturino E. 2009. Spiders as biological controllers in the agroecosystem. Journal of Theoretical Biology 258:352-362. http://dx.doi.org/10.1016/j.jtbi.2008.11.029.

Costello MJ, Daane KM. 2005. Day vs night sampling for spiders in grape vineyards. Journal of Arachnology 33:25-32. http://dx.doi. org/10.1636/H02-52.

Departemen Pertanian. 2004. Pengenalan dan Identifikasi Musuh Alami, Hama dan Penyakit Tanaman Jambu Mete. Jakarta: Departemen Pertanian.

Ellyda AW, Purnayasa GNR, Siswanto. 2001. Potensi cendawan Synnematium sp. sebagai agens pengendali Sanurus indecora (Homoptera: Flatidae). Jurnal Penelitian Tanaman Industri 7:84-87.

Hogg BN, Daane KM. 2010. The rule of dispersal from natural habitat in determining spider abundance and diversity in California vineyards. Agriculture, Ecosystem \& Environment 135:260-267. http:// dx.doi.org/10.1016/j.agee.2009.10.004.
Holt J, Cook AG, Perfectt TJ, Norton GA. 1986. Simulation analysis of brown planthopper (Nilaparvata lugens) population dynamics on rice in the Philippine. Journal of Applied Ecology 24:87-102. http://dx.doi.org/10.2307/2403789.

Moreno CR, Lewins SC, Barbosa P. 2010. Influence of relative abundance and taxonomic identity on the effectiveness of generalist predators as biological control agents. Biological Control 52:96-103. http://dx.doi.org/10.1016/j.biocontrol. 2009.09.004.

Nyffeler M, Sunderland KD. 2003. Composition, abundance and pest control potential of spider communities in agroecosystem: a comparison of European and US studies. Agriculture, Ecosystem \& Environment 95:576-612. http://dx.doi.org/ 10.1016/S0167-8809(02)00181-0.

Öberg S, Mayr S, Dauber J. 2008. Landscape effects on recolonisation patterns of spiders in arable fields. Agriculture, Ecosystem \& Environment 123:211-218. http://dx.doi.org/10.1016/j.agee.2007. 06.005 .

Oka IN, Bahagiawati AH. 1991. Pengendalian Hama Terpadu. Padi: Buku 3. Bogor: Pusat Penelitian dan Pengembangan Tanaman Pangan.

Stella RPT, Sudantha IM, Purnayasa IGNR. 2004. Bioekologi Jamur Synnematium sp. dan Potensinya sebagai Agens Pengendali Hayati Hama Sanurus indecora pada Tanaman Jambu Mete. Laporan Penelitian. Mataram: Universitas Mataram

Suana IW, Solihin DD, Buchori D, Manuwoto S, Triwidodo H. 2005. Kolonisasi dan suksesi labalaba (Araneae) pada pertanaman padi. Jurnal Biologi IX:1-7. 